ISSN 0258-7122 (Print), 2408-8293 (Online)

Bangladesh J. Agril. Res. 41(2): 235-250, June 2016

\title{
STUDY ON MORPHO-PHYSIOLOGICAL TRAITS IN SPRING WHEAT (Triticum aestivum L.) UNDER RAINFED CONDITION
}

\author{
M. RAHMAN ${ }^{1}$, N. C. D. BARMA ${ }^{2}$, B. K. BISWAS ${ }^{3}$ \\ A. A. $\mathrm{KHAN}^{4}$ AND J. RAHMAN
}

\begin{abstract}
Nine morphological and physiological traits were taken to assess genetic parameters, association between the traits and grain yield and partition correlation of yield with other traits, which were purposefully considered as the important strategy for the investigation. Therefore, the main objective of the present investigation was to find out suitable morpho-physiological traits that could be invariably used for the yield improvement of spring wheat grown under drought stress condition. Thirty wheat diverse genotypes were evaluated under drought stress field condition in Alpha Lattice Design with three replications. The study revealed wide range of variability and high broad sense heritability for most of the traits (early ground coverage, canopy temperature, peduncle length, relative water content, number of spikes per $\mathrm{m}^{2}$ and 1,000-grain weight). Genetic advance in percent of mean suggested that there is enough scope for further improvement of genotypes for the characters studied. Correlation studies exhibited that grain yield was positively and significantly associated with early ground coverage and 1000-grain weight. The path analysis also revealed a maximum direct effect on grain yield contributed by 1000-grain weight. Early ground coverage and 1000-grain weight had a significant and spikes per $\mathrm{m}^{2}$ had positive indirect effect on grain yield. Therefore, these three traits were found to be most important for wheat breeding under drought stress. As these traits can be evaluated quickly and easily, hence breeders can choose these traits for selecting potential wheat genotypes for further breeding programs.
\end{abstract}

Keywords: Correlation, Morpho-Physiological Traits, Path analysis, Spring Wheat.

\section{Introduction}

Wheat (Triticum aestivum L.) is economically one of the most important cereal crops in the world. Genetic improvement in wheat yields in dry areas has not been as easy as in more favorable environments or where water is not a limiting factor (Richards et al., 2001). Customarily, drought severely limits wheat productivity in many locations across the globe. Some estimates obviously

\footnotetext{
${ }^{1}$ Regional Wheat Research Centre, Bangladesh Agricultural Research Institute (BARI), Rajshahi, ${ }^{2}$ Regional Wheat Research Centre, BARI, Gazipur, ${ }^{3}$ Department of Genetics and Plant Breeding, Faculty of Agriculture, Hajee Mohammad Danesh Science and Technology University, Dinajpur, ${ }^{4}$ Wheat Research centre, Regional Agricultural Research Station, BARI, Ishurdi, Pabna, ${ }^{5}$ Sher-e-Banlga Agricultural University, Department of Genetics and Plant Breeding, Faculty of Agriculture, Dhaka, Bangladesh.
} 
indicate that approximately $50 \%$ of the 230 million hectares are being cultivated annually with wheat in the world which is regularly affected by drought (Pfeiffer et al., 2005). In dry environments wheat production can be depressed by 50-90\% of the crop potential (Oliveras-Villegas et al., 2007). Additionally, climate change scenarios predict an increase of aridity in the future and certainly water will become an increasingly scarce commodity.

Though Bangladesh is a land of abundant rainfall but drought is very familiar to wheat cultivars. North-western region namely, Barind tract is one of the largest drought affected area of Bangladesh (Brammer, 1999). Besides, each year northwestern region of Bangladesh comprising of 16 districts are also being affected by different levels of drought stress. Farmers' livelihoods of those areas largely depend on rainfed agriculture which is recurrently affected by drought. A joint Bangladesh-FAO soil survey project indicated that 2.3 million hectares of land are physically suitable for wheat under rainfed condition (Begum, 1998).

Undoubtedly, the improvement of drought tolerance is the principal goal in the wheat breeding programs for a long time, since a water deficit in grain filling stage is common in many wheat growing regions of the world. The conventional breeding approach under Wheat Research Centre, BARI has given much emphasis on selecting high yielding advanced lines under optimum growing conditions. Wheat breeding only for yield potential is not the best approach for improving yield under drought conditions as the existing climatic situation is being changed in an irregular and erratic fashion particularly concerning drought. For strengthening wheat improvement program some drought related adaptive traits, for instance relative water content (RWC), canopy temperature, leaf glaucosity/waxiness etc. have been considered for breeding drought tolerant wheat in many wheat growing countries.

Apparently, morpho-physiological traits for growth and development have the greatest impact on the adaptation of plants to the target environments with the aim of achieving a maximum productivity. Selection criteria based on morphological, physiological and biochemical traits have been suggested for screening drought tolerance in wheat. Plant traits, like, water-use efficiency and harvest index (Araus et al., 2002), canopy temperature (Oliveras-Villegas et al., 2007), leaf area, number of grains, grain yield and biological yield (Gupta et al., 2001), RWC \% (Merah, 2001), peduncle length (Kaya et al., 2002), flag leaf chlorophyll content at grain filling stage (Reynolds et al., 2007a) and early ground coverage (Rana et al., 2007) were considered as important drought adaptive traits in wheat. Selection for one trait may or may not offer the chance for a success for other traits, therefore, more than one trait should be considered in selection process. Moreover, preliminary selection of morpho-physiological drought adaptive traits is very important for next generations judicious and careful selection and consequently confirm the outstanding drought tolerant wheat genotypes through appropriate breeding program. Therefore, success of 
such breeding programs mainly depends on the suitable plant morphophysiological traits, which might be considered as the main contributing parameters for drought tolerance in advanced generations. Here, different genetic parameters like coefficient of variation, heritability, genetic advances etc. have been estimated on the morpho-physiological traits that could be used in selecting the potential drought tolerance genotypes.

Different criteria for genetic parameters were assessed to predict the morphophysiological characters under selection for the improvement of yield in wheat. And then all possible correlation coefficients between pairs of characters were estimated to evaluate the degree of association among the morpho-physiological traits including yield of 30 spring wheat genotypes grown under rainfed condition. The correlation coefficients of yield with other morpho-physiological traits were also partitioned into direct and indirect effects to find out a suitable trait that could be used for the yield improvement of spring wheat.

\section{Materials and Method}

\subsection{Plant Materials}

The experimental materials of the study consisted of thirty (30) diverse genotypes of spring wheat (Triticum aestivum L.) including a local check variety 'Shatabdi' (BARI Gom 21), chosen on the basis of their differences in yield and the performance of several physiological traits under rainfed conditions. The genotypes were grown in rainfed plots.

\subsection{Site and Design of the Experiment}

The present study was conducted at the experimental field of the Regional Wheat Research Centre (RWRC), Bangladesh Agricultural Research Institute (BARI), Rajshahi during 2010-11 cropping season. The experimental site was situated between $25.0^{\circ} \mathrm{N}$ latitude and $89.0^{\circ} \mathrm{E}$ longitude with elevation of $28 \mathrm{~m}$. above sea level. The soil of the experimental field was silty clay loam with a $\mathrm{pH}$ value of 7.1-8.5, low in organic matter and fertility level, deficient in boron but rich in iron content. The experiment was laid out in Alpha Lattice design with three replications and recommended production package of RWRC was followed to ensure a good harvest.

\subsection{Soil Moisture and Field Capacity Determination}

The moisture content of the experimental field soil was determined by appropriate gravimetric method. Soil sample was collected randomly from plots of all the 3 replications at 12 days interval starting from 50 days after sowing and continued up to grain filling stage. The following formula was applied to calculate soil moisture content and water at field capacity. 
$\%$ Soil moisture (weight basis): $\frac{\text { Weight of soil moisture }}{\text { Weight of oven dry soil }} \times 100$

Soil moisture contents were $22 \%, 20.16 \%, 18.42 \%$ and $18.00 \%$ after $50,62,74$ and 86 days after sowing (DAS), respectively. The water at field capacity of the experimental field soil was 38\%. Rainfall of $38.4 \mathrm{~mm}$ was recorded at the time of crown root initiation (CRI) stage. No supplementary irrigation was provided as the experiment was conducted under rain-fed condition.

\subsection{Fertilization}

Recommended doses of fertilizers and manures followed by Wheat Research Centre were applied to the field. The crop was fertilized with NPKS and B @ $100,28,40,20$ and $2.5 \mathrm{~kg}$ per hectare, respectively to ensure proper growth and development. The elements N, P, K, S and B were applied in the form of Urea, Triple Super Phosphate, Muriate of Potash, Gypsum and Boric acid, respectively.

\subsection{Parameters of the Experiment and Data Collection}

Early ground coverage was scored visually at 21 days after sowing using 0-10 scale. Canopy temperature was measured using a handheld infrared thermometer (Mikron M90 series, Santa Clara, CA, USA). Canopy temperature was measured 2 times; before heading and grain filling stages. For determination of leaf relative water content (RWC), the leaves from the base of lamina were cut, placed in grip polythene plastic bags and transported in laboratory as quickly as possible. Fresh weights were determined within 2 hours of excision and turgid weight was taken after leaves were soaked in distilled water for 18 hours at room temperature $\left(20 \pm 2^{\circ} \mathrm{C}\right)$ with $60 \%$ relative humidity under low light conditions. The leaves were then taken out of water, blotted on tissue papers and turgid weight was taken. Dry weights were obtained after oven drying the turgid leaves at $70^{\circ} \mathrm{C}$ for 24 hours. Relative water content (RWC) of leaf was calculated using following formula: RWC $(\%)=[($ Fresh weight - Dry weight) $/$ (Turgid weight-Dry weight) $\times 100$. Days to heading (DTH) was counted starting from sowing date to when the spikes completely came out from $50 \%$ of the plants of an individual plot. Peduncle Length was recorded in centimeter from the base of the spike to top culm node. Spikes per square meter were measured at physiological maturity. Thousand grain weight and grain yield (ton per hectare) was measured after harvesting the crop.

\subsection{Analysis of Data}

Descriptive statistical parameters, mean values and the coefficient of variation (CV) were determined for the traits under study. The broad-sense heritability was estimated according to the results obtained by analysis of variance as the ratio of 
the total genetic variance to the total phenotypic variance. Genotypic and phenotypic correlation coefficients between different yield contributing morphophysiological characters were estimated using the following formula as suggested by Miller et al. (1958); Hanson et al. (1956) and Johnson et al. (1955). The correlation coefficients of yield with other morphological traits were partitioned into direct and indirect effects by path co-efficient analysis originally developed by Wright (1921) and later described by Dewey and Lu (1959). In this study, grain yield was considered as the dependent character (effect) and other morphophysiological traits were considered as causal factors.

\section{Results and Discussion}

\subsection{Analysis of Genetic Components of Variation for the Yield and Morpho- Physiological Traits}

Analysis of variance $(\mathrm{P}<0.01)$ revealed differential expression of the selected characters and indicated the prevalence of genetic variability among the 30 spring wheat genotypes. The estimates of different genetic parameters against the morphophysiological traits and grain yield of 30 spring wheat genotypes are presented in Table 1. Estimation of different genetic parameters is imperative to unravel the genetic basis of different traits that can contribute to crop yield. This indicated that there was some degree of environmental influence on early ground coverage and at the same time narrow range of genetic variation for this trait could be realized.

Most of the traits under study showed high estimate of broad sense heritability $\left(\mathrm{h}^{2} \mathrm{~b}\right)$ except spikes per $\mathrm{m}^{2}$ and indicated higher to moderate genetic advance except canopy temperature (CT) at vegetative stage. Kandic et al. (2009) observed that early vigor was highly significant with high heritability and genetic advance in wheat. The low and close GCV and PCV indicated narrow range of genotypic variability caused by fixed alleles and less influence of environment for the expression of the traits. This study corroborated with the studies of Rahman (2009) who reported a narrow range of variation among wheat genotypes for these traits. Higher estimate of broad sense heritability along with moderate genetic advance suggested majority were additive, hence, improvement through phenotypic selection for these traits are feasible. Reynolds et al. (1997) reported sensitivity of canopy temperature to environmental fluxes along with moderate heritability in bread wheat.

Canopy temperature measured by infrared thermometer to evaluate the genotypes for their ability to keep canopy cool with less impaired assimilation processes. At vegetative stage the PCV (1.645) was higher than GCV (0.786) against canopy temperature, which indicated that the environment itself had played major role for the expression of this trait. Rahman (2009) observed lower genetic advance along with moderate heritability for canopy temperature in spring wheat. Yadav et al. (2001) showed that relative water content (RWC) decreased significantly under soil water condition and Shamsi et al. (2010) reported that high relative 
water content is a resistant mechanism to drought in wheat. Chaturvedi and Gupta (1995) found higher phenotypic variation than the genotypic variation and obtained higher estimates of heritability for 1000-grain weight (TGW). High heritability along with high genetic advance was found for TGW, which was also observed by some other authors (Ali et al., 2008). Drought imposed during later stage might additionally cause a reduction of number of grain per spike and grain weight (Gupta et al., 2001; Dancic et al., 2000). Many authors found high heritability along with high to moderate genetic advance for grain yield in wheat (Barma, 2002; Singh et al., 2006; Ali et al., 2008; Rahman, 2009). The heritability of the most important trait i.e. grain yield (GY) was rather high (over $80 \%$ ) clearly indicated higher influence of genetic factors than the environment on the expression of this trait. This finding is in agreement with the findings of Kashif and Khaliq (2004) and Ul-Haq et al. (2008).

\subsection{Analysis of Correlations between Yield and Different Morpho- Physiological Traits}

The information of correlations among different plant traits can be of great use to breeders, as it points out to the traits to which selection should be directed in order to increase the yield under certain environmental conditions. Genetic correlations point to the cohesion of traits after variations due to environmental effects are eliminated and they are the basis for the indirect selection (Van Ginkel et al., 1998). Genotypic and phenotypic correlations between the yield and physiological traits are presented in Table 2. Significant and positive genotypic and phenotypic correlations with the yield were observed for EGC $(P<0.01)$ in this study. EGC also had strong positive association with TGW. At phenotypic level spike per $\mathrm{m}^{2}$ was also positively but non-significantly associated with EGC. Negative correlation was found in case of canopy temperature at grain filling stage with all other traits.

Positive association of EGC with yield and TGW suggested that higher ground coverage at early stage could lead to higher biomass which might offer production of more photosynthates and finally contributed to TGW and grain yield. Kandic et al. (2009) also noticed a significant and positive genotypic and phenotypic correlation with the yield which was observed for EGC. Rapid early plant growth rate is an important trait because it reduces soil evaporation and increases the competitiveness of wheat plants against weeds.

Peduncle length (PdL) showed negative correlation with TGW, grain yield and spike per $\mathrm{m}^{2}$ at both genotypic and phenotypic levels (Table 2). Gautam and Sethi (2002) observed that negative association with spikes/plant, plant height, spikelets per spike, days to maturity and heading. Naik (2000) also reported significant negative association with grain yield under drought condition for these traits. Amin et al. (2013) observed positive correlation of peduncle length with plant height and spike length but noticed no correlation with grain yield under terminal drought stress condition. 


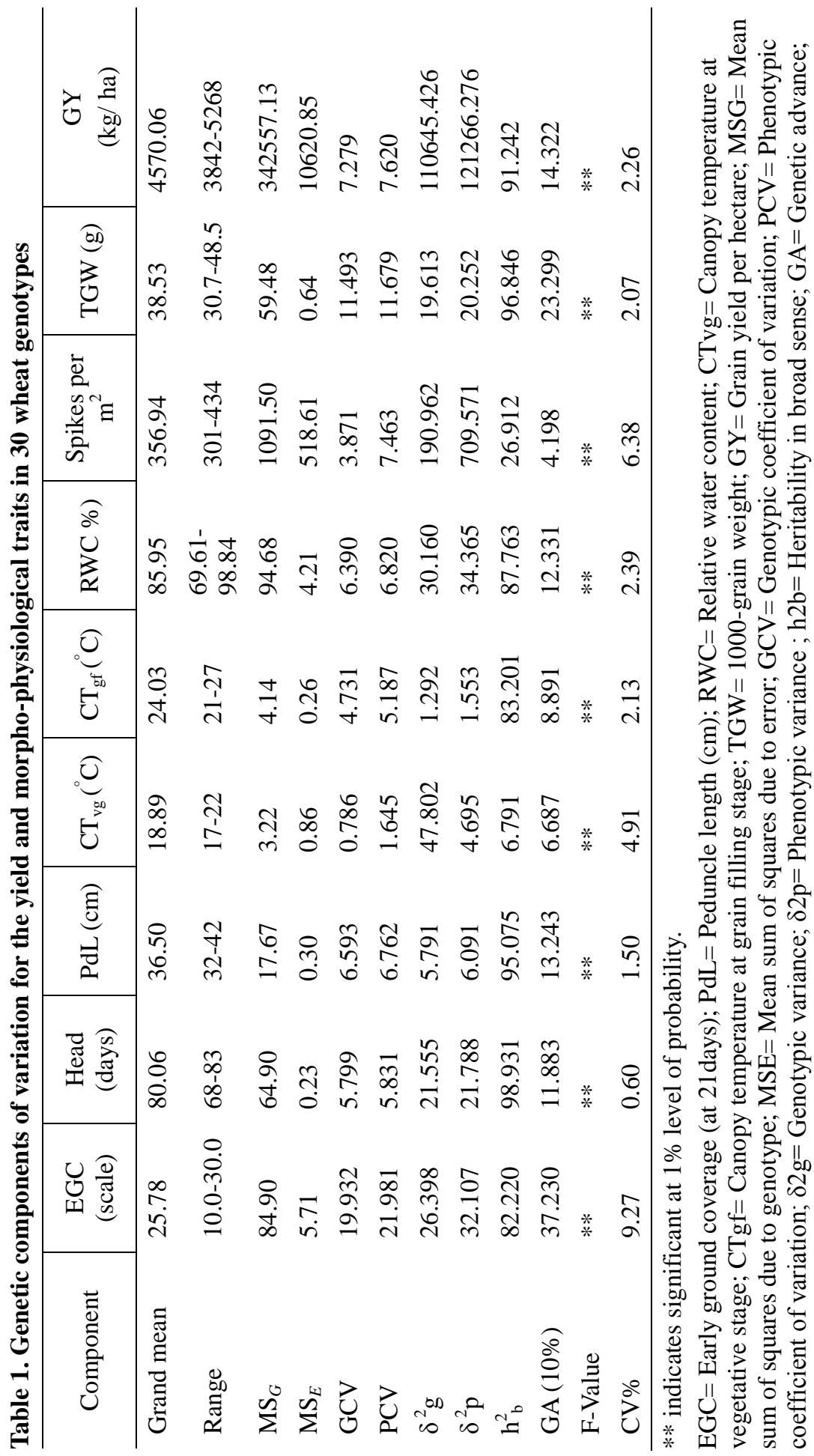




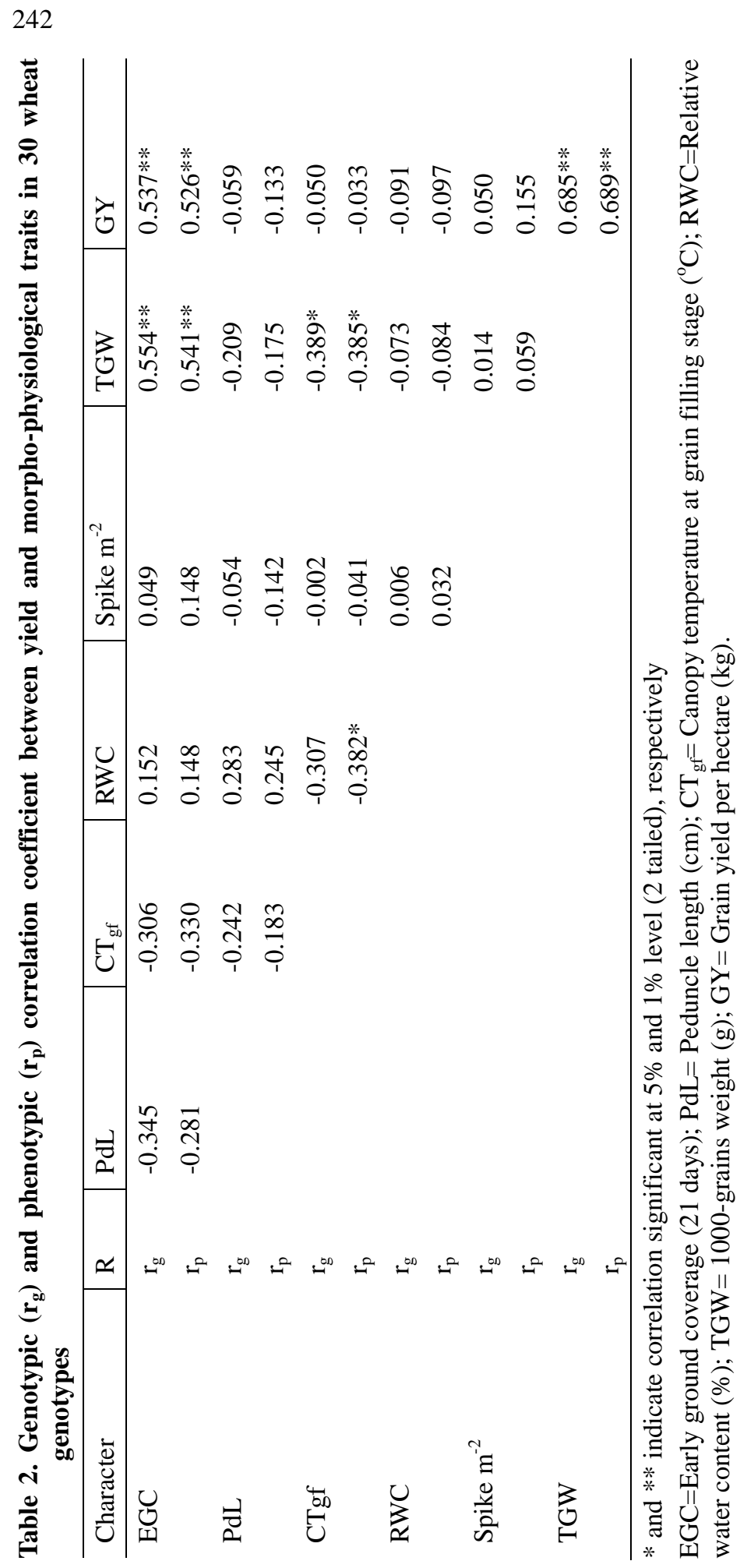

RAHMAN et al. 
Canopy temperature (CT) at grain filling stage had negative correlation with grain yield at genotypic $\left(r_{g}=-0.050\right)$ and phenotypic levels $\left(r_{p}=-0.033\right)$. Significant negative correlation also observed with TGW at genotypic $(-0.389)$ and phenotypic (-0.385) levels and with RWC at phenotypic (-0.382) level only. Number of grains spike per $\mathrm{m}^{2}$ had non-significant negative correlation with CT at genotypic and phenotypic levels. Rahman (2009) reported strong and negative correlation of $\mathrm{CT}_{\mathrm{gf}}$ with grain yield. Rahman et al. (1997) also observed that high yielding genotypes possessed significantly low canopy temperature and medium chlorophyll content. Balota et al. (2007) also observed significant correlation coefficients of $\mathrm{CT}$ at three developmental stages i.e. pre-heading, heading and post-anthesis with grain yield. Therefore, CT might be used as a selection criterion to improve adaptation to drought and heat. CIMMYT began CT measurements on different irrigated experiments in Northwest Mexico and it was found that phenotypic correlations of CT with grain yield were occasionally positive (Fischer et al., 1998). They also reported that CT has been using as a selection criterion for tolerance to drought and high temperature stress in wheat breeding program especially in early segregating generations like $F_{3}$.

Relative water content (RWC) had negative and non-significant correlation with grain yield at genotypic $\left(r_{g}=-0.091\right)$ and phenotypic levels $\left(r_{p}=-0.097\right)$. It was also found negative correlation with TGW at genotypic and at phenotypic levels (Table 2). Interestingly, this trait had insignificant positive association with spikes per both at genotypic and phenotypic levels. It was found that RWC decreases with concurrent increase of drought stress usually but not always in wheat under drought stress conditions; the cultivars that were resistant to drought have more RWC. Shamsi et al. (2010) observed positive correlation with grain yield in drought condition and also reported that with an increase in the intensity of drought stress on wheat cultivars there was a decrease in relative water content. Siegien and Leszezynska (2004) also observed significant correlation between grain yield and RWC.

Spikes per $\mathrm{m}^{2}$ had positive correlation both at genotypic and phenotypic levels with TGW and grain yield. Several investigators found spikes per $\mathrm{m}^{2}$ to be correlated significantly and positively with grain yield (Burio et al., 2004; Munir et al., 2007 and Akram et al., 2008). Thousand grain weight (TGW) showed significant positive correlation with grain yield both at genotypic (0.685) and phenotypic (0.689) level. Guttieri et al. (2001) observed that grain weight per spike decreased due to drought during grain filling period. Several authors (Nayeem et al., 2003; Jat et al., 2003; Zecevic et al., 2004) had reported significant and positive correlation of TGW with grain yield in wheat. 


\subsection{Analysis of Direct and Indirect Effects of Different Morpho-Physiological Traits on Grain Yield}

The correlation coefficients usually measure the mutual association between a pair of independent variables. But when more than two variables are involved, the correlations do not give the complete information of their accurate relationships. Additionally, the path coefficient analysis is particularly useful for the study of the cause and effect relationship, because it simultaneously considers several variables in data set to obtain the coefficients. Herein, path analyses of morpho-physiological traits on grain yield are sown in Table 3 .

Early ground coverage (EGC) had a positive direct effect on yield (0.273). This trait also had indirect positive effect on yield via RWC, spike per $\mathrm{m}^{2}$ and TGW. Furthermore, it concomitantly resulted to a significant positive correlation with yield at genotypic level (Table 2). The importance of total biomass for the yield increase in wheat, especially under drought stress conditions is already established (Reynolds et al., 2007b). A higher biomass production under drought stress conditions, particularly during grain filling period, would have an advantage because the translocation of assimilates from the vegetative parts of a plant to seeds contribute significantly to yield.

Peduncle length had direct positive effect on grain yield (0.149). This trait had maximum indirect negative effect on yield via EGC (-0.040) followed by CT and TGW. The effects on yield via other physiological traits were found negligible. Thus, it resulted to a negative correlation with yield at genotypic level. Almost similar findings were reported by Khan et. al. (2010) in wheat under drought stress condition.

Canopy temperature at grain filling stage $\left(\mathrm{CT}_{\mathrm{gf}}\right)$ had direct positive $(0.323)$ effect on yield. This trait had maximum indirect negative effect on yield via EGC (0.089) followed by PdL (-0.078). A number of negative indirect effects on grain yield were observed for canopy temperature via yield contributing traits like, leaf area index, grains per spike, spikes per $\mathrm{m}^{2}$ and plant height, grain weight etc. All these ultimately led to negative correlation with yield at genotypic association level (Table 3). The present findings are corroborated with the results as observed by Mohammadi et. al. (2014).

Relative water content (RWC) had an insignificant negative direct effect (-0.013) on grain yield which led to negative correlation co-efficient between relative water content and grain yield. Positive indirect effects on yield were observed for this trait via lower canopy temperature at grain filling stage. Similar findings were reported by Arjenak et al. (2012) in their study with some wheat varieties under drought stress condition. 


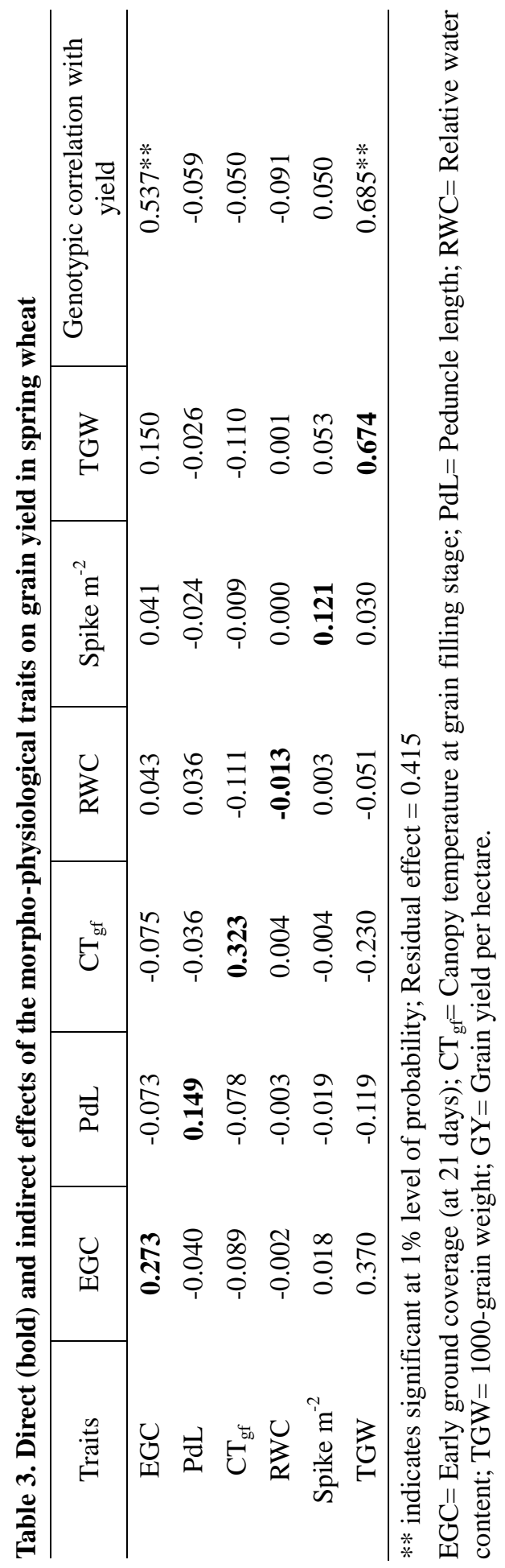


Spikes per $\mathrm{m}^{2}$ had direct positive effect on grain yield (0.121). This trait had a number of indirect positive effects on yield via most of the other traits studied. It has shown maximum indirect positive effect via grain weight and early ground coverage. Most of these positive indirect effects were of low in magnitude. Ultimately this trait was found associated with yield having positive correlation coefficient at genotypic level. Chaturvedi and Gupta (1995) reported positive direct effect of spikes per $\mathrm{m}^{2}$ on yield which supported this perception.

Thousand Grain weight (TGW) showed direct positive effect on grain yield (0.674). This trait had maximum indirect positive effect on yield via early ground coverage $(0.370)$ followed by grains per spike $(0.030)$. Ultimately this trait had significantly positive correlation ().685) with yield at genotypic level. Ibrahim (1994) also observed direct positive effect of TGW on grain yield.

Finally, path analysis for primary yield contributing characters revealed that spikes per $\mathrm{m}^{2}$, canopy temperature and TGW contributed considerable amount of positive direct effects on grain yield. These direct effects obviously were the principal components of their relationships with yield. Similar findings were reported by Shamsuddin and Ali (1989). According to the authors spikes per plant and TGW were correlated with yield mainly through their direct effects.

\section{Conclusions}

In conclusion, traits such as early ground coverage had positive correlation and had an indirect effect on grain yield. Moreover, early ground coverage, spikes per $\mathrm{m}^{2}$ and TGW had positive correlations with grain yield. Most importantly, as early ground coverage, spikes per $\mathrm{m}^{2}$ and TGW can be evaluated quickly as well as easily and hence, it is suggested that more emphasis should be given on the morpho-physiological (phenological and physiological) characters for selecting wheat genotypes with higher grain yield under rainfed condition.

\section{Acknowledgments}

The authors acknowledge the assistance of the Regional Wheat Research Centre, Bangladesh Agricultural Research Institute (BARI), Rajshahi, for supporting this work, along with the Bangladesh Agricultural Research Institute for providing a student scholarship for the lead author.

\section{References}

Akram, Z., S. U. Ajmal, and M. Munir, 2008. Estimation of correlation coefficient among some yield parameters of wheat under rainfed condition. Pakistan J. Bot. 40: 17771781.

Ali, Y., B. Manzoor, J. Akhter, P. Monneveux, and Lateef Z, 2008. Genetic Variability, Trait Association and Diversity Studies in Wheat. Pakistan J. Bot. 40: 2087-2097. 
Amin, R., S. Bahraminijad and S. Jalali-Honarmand.2013. Effect of terminal drought stress on grain yield and some morpho-physiological traits in 80 bread wheat genotypes. Intl. J. Agri. Crop Sci. Vol 5(10):1145-1153.

Araus, J. L., G. A. Slafer, M. P. Reynolds, and C. Royo, 2002. Plant breeding and water relations in C3 cereals: what should we breed for? Annals of Botany. 89: 925-940.

Arjenak, F. G., R. Jabbari and A. Morshedi. 2012. Evaluation of drought stress on relative water content, chlorophyll content and mineral elements of wheat (Triticum aestivum L. varieties. Int. J. Agric. Crop. Sci. 4(11): 726-729.

Balota, M., W. A. Payne, S. R. Evett, and M. D. Lazar, 2007. Canopy temperature depression sampling to assess grain yield and genotypic differentiation in winter wheat. Crop Sci. 47: 1518-1529.

Begum, R., 1998. An economic study of wheat production and marketing in Bangladesh. Ph.D disseration. The United Graduate School of Agricultural Science, Ehime University, Matsuyama, Japan. P. 194.

Brammer, H., 1999. Agricultural disaster management in Bangladesh. University Press Limited. Pp. 273-74, 331.

Burio, U. A., F. C. Oad, and S. K. Agha, 2004. Correlation coefficient (r) values of growth and yield components of wheat under different nitrogen levels and placements. Asian J. of Plant Sci. 3:372-374.

Chaturvedi, B. K., and R. R. Gupta, 1995. Selection parameters for some grain and quality attributes in spring wheat. Agril. Sci. Digest. 15: 186-190.

Dancic, S., R. Kastori, B. Kobiljski, and B. Duggan, 2000. Evaluation of grain yield and its components in wheat cultivars and landraces under near optimal and drought conditions. Euphytica. 113: 43-52.

Dewey, D. R., and K. H. Lu, 1959. A Correlation and path-coefficient analysis of components of crested wheatgrass seed production. Agronomy J. 51: 515-518.

Fischer, R. A., D. Rees, K. D. Sayre, Z. M. Lu, A. G. Condon, and A. L. Saavedra, 1998. Wheat yield progress associated with higher stomatal conductance and photosynthetic rate, and cooler canopies. Crop Sci. 38: 1467-1475.

Gautam, R. K., and G. S. Sethi, 2002. Character association in Secale cereale L. introgressed bread wheat under irrigated and water stress conditions. Indian J. of Gen. and Plant Breed. 62: 69-70.

Guttieri, M. J., J. C. Stark, K. Obrien, and E. Souza, 2001. Relative sensitivity of spring wheat grain yield and quality parameters to moisture deficit. Crop Science. 41: 327335 .

Gupta, N. K., S. Gupta and A. Kumar. 2001. Effect of water stress on physiological attributes and their relationship with growth and yield in wheat cultivars at different growth stages. J. Agron. 86: 1437-1439.

Hanson, C. H., H. F. Robinson, and R. E. Comstock, 1956. Biometrical studies of yield in segregating population of Korean lespedeza. J. Agron. 48: 268-272. 
Ibrahim, K. I. M., 1994. Association and path coefficient analysis of some traits in some bread wheat. Ann. Agril. Sci. 32: 1189-1198.

Jat, B. L., and L. L. Dhakar, 2003. Correlation and regression studies in wheat. Environment and Ecology. 21(1): 34-36.

Johnson, H. W., H. F. Robinson, and R. K. Comstock, 1955. Estimation of genetic and environmental variability in soybean. J. Agron. 47: 314-318.

Kaya, Y., R. Topal, A. E. Gonulal, and R. Z. Arisoy. 2002. Factor analyses of yield traits in genotypes of durum wheat (Triticum durum). Indian J. Agril. Sci. 72: 301-303.

Kandic, V., D. Dodig, M. Jovic, B. Nikolic, and S. Prodanovic, 2009. The importance of physiological traits in heat breeding under irrigation and drought stress. Genetika. 41: 11 -20.

Kashif, M., and I. Khaliq, 2004. Heritability, correlation and path coefficient analysis for some metric traits in wheat. In. J. Agril. \& Biol. 6: 138-142.

Khan A. J., F. Azman and A. Ali. 2010. Relationship of morphological traits and grain yield under drought conditions. Pakistan J. Bot. Vol. 421):259-267.

Merah. O., 2001. Potential importance of water status traits for durum wheat improvement under Mediterranean conditions. J. Agril. Sci. 137: 139-145.

Miller, P. J., J. C. Williams, H. F. Robinson, and R. E. Comstock, 1958. Estimation of genotypic and environmental variances and covariances in upland cotton and their implication in selection. Agronomy J. 50: 126-131.

Mohammad,i M., P. Sharifi and R. Karimizadeh. 2014. Sequential Path analysis for determination of relationship between yield and yield components in Bread wheat (Triticum aestivum L.). Not. Sci. Biol. Vol. 6(1):119-124.

Munir, M., M. A. Chowdhury, and T. A. Malik, 2007. Correlation studies among yield and its components in bread wheat under drought conditions. In. J. Agril. and Biol. 9: 287-290.

Naik, V. R., 2000. Genetic analysis of heat and drought tolerance in tetraploid wheat. Ph.D.Thesis, University of Agricultural Sciences, Dharwad.

Nayeem, K. A., K. S. Baig, and N.S. Karad, 2003. Genetic variability and character association studies for export quality parameters in Triticum durum wheat. $J$ Res. Angrau. 30: 5-10

Oliveras-Villegas, J. J., M. P. Reynolds, and G. K. McDonald, 2007. Drought-adaptive attributes in the Seri/Babax hexaploid wheat population. Functional Plant Biology. 34: 189-203.

Pfeiffer, W. H., R. M. Trethowan, K. Ammar, and K. D. Sayre, 2005. Increasing yield potential and yield stability in durum wheat. Durum Wheat Breeding Current Approaches and Future Strategies. Food Products Press, New York. P. 531-544

Rahman, M. M., 2009. Genetic variation in the duration of growth stages and their relationship with yield and yield components in spring wheat under two sowing environments. M.S. Thesis, Bangladesh Agricultural University, Mymensingh. 
Rahman, M. M., A. B. S. Hossain, N. K. Saba, and P.K. Malaker, 1997. Selection of morpho-physiological traits for heat tolerance in wheat. Bangladesh J. Scienti. and Indust. Res. 32: 161-165

Rana, M., and R. A. Richards, 2007. Advances in Molecular Breeding toward drought and salt tolerant crops. Springer Link. p 565-585.

Reynolds M., F. Dreccer and R. Trethowan. 2007a. Drought adaptive traits derived from wild relatives and landraces. J. Expt. Bot. 58(2):177-186.

Reynolds, M. P., S. Nagrajan, M. A. Razzaque and O. A. A. Ageeb, 1997. Using Canopy Temperature Depression to select for yield potential of wheat in heat-stressed environments. Wheat Program Special Report. CIMMYT. Mexico. P. 42

Reynolds, M. P., P. C. Saint, and M. Vargas, 2007b. Evaluating Potential Genetic Gains in Wheat Associated with Stress-Adaptive Trait Expression in Elite Genetic Resources under Drought and Heat Stress. Crop Sci. 47: 172-189

Richards, R. A., A.G. Condon, and G.J. Rebetzke, 2001. Traits to Improve Yield in Dry Environments. In: M.P. Reynolds, J.I. Ortiz-Monasterio, and A. McNab (eds.), Application of Physiology in Wheat Breeding. Mexico, D.F.: CIMMYT.

Shamsi, K., M. Petrosyan, G. Noor-mohammadi, A, Haghparast, S. Kobraee, and B. Rasekhi, 2010. Differential agronomic responses of bread wheat cultivars to drought stress in the west of Iran. African J. Biotech. 10: 2708-2715.

Shamsuddin, A. K. M., and M. M. Ali, 1989. Genotypic and phenotypic correlation and path analysis in spring wheat. Bangladesh J. Agril. Sci. 16: 75-78.

Sharma, P. K., P. K. Gupta, and H. S. Balyan, 1998. Genetic diversity in a large collection of wheats (Triticum spp). Indian Journal of Genetics and Plant Breeding. 58: 271278.

Shamsi, K., 2010. The effects of drought stress on yield, relative water content, proline, soluble carbohydrates and chlorophyll of bread wheat cultivars. J. Animal \& Plant Sci. 8: $1051-1060$.

Siegien, N., and R. B. Ieszezynska, 2004. Effects of drying rate on dehydration sensitivity of excised wheat seedling shoots as related to sucrose metabolism and antioxidant enzyme activities. Plant Science. 167: $879-888$.

Singh, K. N., K. Neeraj, V. Kumar, and S. Tim, 2006. Genetic variability of wheat (Triticum aestivum) lines for grain yield and component characters grown under sodic and waterlogged conditions. Indian Journal of Agriculture Science. 76: 414419.

Ul-Haq, W., M. F. Malik, M. Rashid, M. Munir, and Z. Akram, 2008. Evaluation and estimation of heritability and genetic advancement for yield related attributes in wheat lines. Pakistan J. Bot. 40: 1699-1702.

Van, G. M., D. S. Calhoun, G, Gebeyehu, A. Miranda, C. Tian-You, R. P. Lara, R. M. Trethowan, K. Sayre, J. Crossa, and S. Rajaram, 1998. Plant traits related to yield of wheat in early, late, or continuous drought conditions. Euphytica. 100: 109-121.

Wright, S., 1921. Correlation and causation. J. Agril. Res. 1: 557-585. 
Yadav, R. S., K. Gaydian, and A. K. Jaiswal, 2001. Morpho-physiological changes and variable yield of wheat genotypes under moisture stress conditions. Indian J. Plant Physiol., 5: 390-394.

Zecevic, V., D. Knezevic, and D. Micnovic, 2004. Genetic correlation and path coefficient analysis of yield and quality components in wheat (Triticum aestivum L.). Genetica. 36: 13-21. 